\title{
Clinical efficacy of low-dose inhaled budesonide once or twice daily in children with mild asthma not previously treated with steroids
}

\author{
G. Jónasson*, K-H. Carlsen+, P. Blomqvist
}

Clinical efficacy of low-dose inhaled budesonide once or twice daily in children with mild asthma not previously treated with steroids. G. Jónasson, K-H. Carlsen, P. Blomqvist. CERS Journals Ltd 1998.

ABSTRACT: The aim of the present study was to examine the efficacy of low-dose inhaled budesonide (BUD) administered via Turbuhaler ${ }^{\circledR}$ once or twice daily on symptoms, lung function and bronchial hyperreactivity in children with mild asthma.

One hundred and sixty-three children (mean age 9.9 yrs, 56 females/107 males) with mild asthma (forced expiratory volume in one second (FEV1) $103 \%$ of predicted, morning peak expiratory flow (PEF) 87\% pred, reversibility in FEV1 3\%, fall in FEV1 after exercise $\mathbf{1 0 . 4 \%}$ from pre-exercise value) and not previously treated with inhaled steroids, were included in a double-blind, randomized, parallel-group study. After a two-week run-in period, the children received inhaled BUD $100 \mu \mathrm{g}$ or $200 \mu \mathrm{g}$ once daily in the morning, $100 \mu \mathrm{g}$ twice daily or placebo for 12 weeks. Exercise and methacholine challenges were performed before and at the end of treatment.

After 12 weeks of therapy, the fall in FEV1 after an exercise test was significantly less in all three BUD groups $(4.3-5.1 \%)$ than in the placebo group (8.6\%). Bronchial hyperreactivity to methacholine with the provocative dose causing a $20 \%$ fall in FEV1 decreased significantly in the BUD $100 \mu \mathrm{g}$ twice-daily group compared with placebo (ratio at the end of treatment 156\%). Changes in baseline lung function (FEV1 and PEF) were less marked than changes in bronchial responsiveness.

In conclusion, low doses of inhaled budesonide, given once or twice daily, provided protection against exercise-induced bronchoconstriction in children with mild asthma and near normal lung function.

Eur Respir J 1998; 12: 1099-1104.

The goal of asthma therapy in children is to allow them to be involved in normal everyday activities, including full participation in exercise and sports. There should not be excessive absence from school and children should be free from symptoms day and night. Lung function should be normalized, with low diurnal variation in peak expiratory flow (PEF) [1]. At present, glucocorticosteroids are the most effective anti-inflammatory drugs in the treatment of asthma and inhaled steroids are now recommended as first-line therapy in children with severe or moderate asthma. Treatment recommendations for children with mild, persistent asthma include either a low dose of the inhaled steroid cromolyn or nedocromil [2]. Long-term studies in children with asthma have shown that early intervention may prevent the development of irreversible airway obstruction [3, 4]. In the past few years, inhaled steroids have been introduced in the treatment of mild asthma with a recommended dose of 50-200 $\mu \mathrm{g}$ twice daily [5]. However, there is evidence to suggest that the lowest possible dose should be used to control asthma symptoms, since systemic effects of glucocorticosteroids are dose-dependent [6-8]. Previous studies have shown that low doses $(100-200 \mu \mathrm{g})$ of inhaled steroids may be effective in controlling asthma symptoms in children, without causing apparent systemic side-effects [9-11].
*Paediatric Section for Allergy and Pulmonology, Ullevål Hospital, Oslo, Norway. +Voksentoppen, Centre of Allergy and Asthma in Children, Oslo, Norway. *Clinical Research and Development, Astra Draco, Lund, Sweden.

Correspondence: G. Jónasson

Paediatric Section for Allergy and Pulmonology

Ullevål Hospital

$\mathrm{N}-0407$ Oslo

Norway

Fax: 4722118663

\section{Keywords: Asthma}

bronchial hyperreactivity

budesonide

children

exercise-induced asthma

inhaled corticosteroids

Received: February 61998

Accepted after revision June 281998
In the present paper, a randomized, double-blind, placebo-controlled trial of low doses of inhaled budesonide (BUD) given once or twice daily in children with mild asthma is described.

Patients and methods

\section{Study design}

The study was a double-blind, single-centre trial. A two-week open run-in period, which served as a baseline and during which the children were introduced to the Turbuhaler® inhaler (Astra Draco, Lund Sweden), a peak flow meter and completing a diary, was followed by a 12 -week double-blind treatment period with five visits to the clinic (at enrolment, at randomization and at fourweek intervals). Patients were randomized into four parallel groups in balanced blocks. At randomization, each patient received two Turbuhaler inhalers, one to be used in the morning and the other in the evening. Group I patients were given BUD $100 \mu \mathrm{g}$ once daily in the morning and placebo in the evening. Group II received BUD $200 \mu \mathrm{g}$ once daily in the morning and placebo in the evening. 
Group III received BUD $100 \mu \mathrm{g}$ twice daily. The remaining group, group IV, received placebo twice daily.

The patients kept daily records of peak flow values, symptoms, use of $\beta_{2}$-agonists and intake of study medication. Clinical assessments and lung function tests (flowvolume curve and plethysmography) were performed at four-week intervals. Exercise tests were performed at enrolment and at the end of the 12-week treatment period. Measurement of the provocative dose of methacholine causing a $20 \%$ fall in the forced expiratory volume in one second (PD20) was performed at randomization and after 12 weeks of treatment. After completing the baseline lung function tests and the exercise test at enrolment, a reversibility test to inhaled terbutaline was performed. Pulmonary function testing was performed at approximately the same time of the day for each patient. The exercise test and the methacholine provocation were performed on separate days.

The study was approved by the Regional Medical Ethics Committee in Oslo.

\section{Patients}

A total of 163 children with mild asthma were included in the study (107 male and 56 female, aged 7-16 yrs). A total of 166 patients were enrolled in the run-in period of the study and three discontinued prior to randomization. Two of these were excluded because their asthma deteriorated and one patient because of noncompliance. Patients were selected from the outpatient clinic at the Section of Allergy and Pulmonology, Dept of Paediatrics, Ullevål University Hospital in Oslo.

Inclusion criteria were the diagnosis of asthma, based on the definition in the International Consensus report [12] and in the Nordic Consensus report [13], with three previous obstructive episodes or one previous obstructive episode with atopy. At least one of these episodes had to have occurred within the year prior to the first visit. The patients did not use inhaled steroids within 2 months, or cromoglycate and/or nedocromil within 4 weeks of entry. No patient had any lower respiratory tract infection or exacerbation of asthma requiring an emergency room visit and/or hospitalization in the 4 weeks prior to entry.

\section{Methods}

BUD (daily dose $100 \mu \mathrm{g}$ or $200 \mu \mathrm{g}$ ) or placebo was inhaled from Turbuhaler in the morning and evening during the 12 -week treatment period. The patients were instructed to rinse their mouths out with water after each use. All patients were supplied with terbutaline (Bricanyl Turbuhaler® $250 \mu \mathrm{g}$ ), to be used as needed during the study. Children were required to demonstrate that they were competent in using Turbuhaler before enrolment, after the run-in period, and thereafter at four-week intervals during the study. A Vitalograph ${ }^{\circledR}$ peak flow meter (Vitalograph, Ennis, Ireland) was dispensed at enrolment. Patients measured their PEF every morning and evening throughout the entire study period. The highest PEF value from three exhalations was recorded on each occasion. At each clinic visit, staff checked that the children could use the PEF meter correctly. Patients were instructed to fill in a diary twice daily, recording intake of study medication as well as rescue medication, PEF values, and symptom score. Asthma symptoms were scored on a four-point scale, which ranged from 0 (no symptoms) to 3 (severe symptoms). The diary sheet was collected at every visit.

Exercise-induced bronchoconstriction. This was determined at enrolment and at the end of the 12-week treatment period by the use of a motor-driven treadmill, where the children were instructed to run for 6 min with a submaximal exercise load [14]. The inclination of the treadmill was $5.5 \%$ and the speed was adjusted to a submaximal load to achieve a steady-state cardiac frequency of 170180 beats min $^{-1}$. The cardiac frequency was recorded electronically (Sport-Tester® PE 3000 with memory function: Polar Electro KY, Kempele, Finland). The submaximal run on the treadmill was performed at the same speed (exercise load) on both test occasions (at randomization and after 12 weeks of treatment) for each individual child. Forced expiratory volume in one second (FEV1) was measured before running, immediately after, and 3, 6, 10 and 15 min after running. The maximum percentage fall in FEV1 after the exercise test was calculated by:

(Pre-exercise FEV1 - Minimum post-exercise FEV1) $\times 100$ Pre-exercise FEV1

Bronchial hyperreactivity. This was measured at randomization and at the end of the 12-week treatment period by a methacholine chloride inhalation test for the determination of PD20, [15]. Methacholine was inhaled in doubling doses from $0.128 \mu \mathrm{mol}$ up to a maximum dose of 16.32 $\mu$ mol or until FEV 1 had fallen Š20\% compared with FEV1 after an initial saline (0.9\%) inhalation. The bronchial aerosol provocation system (APS) (Jaeger, Würzburg, Germany) with the Sandoz nebulizer (Jaeger) were used for this procedure. The Sandoz nebulizer was calibrated to nebulize $5 \mu \mathrm{L}$ per nebulization and was triggered by inspiration on tidal ventilation. Each nebulization lasted for $0.5 \mathrm{~s}$. Lung function was measured $1 \mathrm{~min}$ after each inhaled dose. PD20 was determined by linear interpolation on a semilogarithmic scale $[15,16]$.

If the patient had inhaled a $\beta_{2}$-agonist within $8 \mathrm{~h}$ prior to the lung function tests, the challenge was postponed until the next day.

Lung function. This was measured at every visit using maximal forced expiratory flow-volume curves and wholebody plethysmography (Masterlab Body; Jaeger) under body temperature, barometric pressure, saturated with water vapour (BTPS) conditions. Predicted lung function values were calculated using reference values from ZAPLETAL et al. [17]. At least three independent flow-volume curves were obtained on each visit and the curve with the highest FEV1 was chosen. Values for the forced expi-ratory flow at $25 \%$ of the forced vital capacity (FEF25\%), FEF50\% and FEF75\% were also obtained from selected flow-volume curves. Calibrations were carried out daily on all lung function measuring equipment used in the study. Reversibility was tested at the entry visit, $15 \mathrm{~min}$ after administration of $500 \mu \mathrm{g}$ of inhaled terbutaline from Turbuhaler. 
Adverse events. Information was obtained at each visit by asking the patients or guardian "Have you/your child had any health problems or symptoms not usually associated with your/his/her asthma since the last visit?" The onset, severity and outcome of each adverse event were recorded.

\section{Sample size}

It was assumed that the standard deviation of a change in morning PEF was $30 \mathrm{~L} \cdot \mathrm{min}^{-1}$ and with 40 patients per treatment group there would have been an $80 \%$ chance of detecting a difference of $20 \mathrm{~L} \cdot \mathrm{min}^{-1}$ between two treatment effects when using a two-sided t-test with a significance level of $\mathrm{p}<0.05$.

\section{Statistical evaluation}

The change from baseline to the end of treatment was subjected to analysis of variance (ANOVA) with treatment as a factor and baseline value as a covariate. The ANOVA was used to obtain estimates of the pairwise differences between treatment effects and the standard deviation of each pairwise difference between treatment effects. An additive model was used when analysing diary variables, lung function variables and the maximum fall in FEV1 after the exercise test, whereas a multiplicative model was used when analysing plethysmography variables and PD20. The efficacy of BUD $100 \mu \mathrm{g}$ once daily and placebo was compared using a two-sided t-test at a $\mathrm{p}<0.05$ significance level. The effect of BUD $200 \mu \mathrm{g}$ once daily and BUD 100 $\mu \mathrm{g}$ once daily was compared in the same manner. The statistical analysis was based on the All Patients Treated approach; thus, all patients who had received at least one dose of study medication were included. Missing values were handled by applying the Last Value Extended principle. For diary variables, this was accomplished by extending the period means.

\section{Results}

The 163 randomized patients had a mean age of $9.9 \mathrm{yrs}$, a mean weight of $37.7 \mathrm{~kg}$ and a mean height of $143.4 \mathrm{~cm}$

Table 1. - Patient characteristics at baseline for each treatment group

\begin{tabular}{lcccc}
\hline Characteristics & BUD & BUD & BUD & Placebo \\
& 100 b.i.d. & 200 o.d. & 100 o.d. & \\
\hline Number of patients & 40 & 42 & 41 & 40 \\
Males/Females & $26 / 14$ & $23 / 19$ & $31 / 10$ & $27 / 13$ \\
Age yrs & 10.2 & 10.0 & 9.8 & 9.6 \\
Height cm & 145.4 & 144.9 & 142.1 & 141.2 \\
Atopics n & 26 & 25 & 31 & 28 \\
FEV1 L & 2.34 & 2.21 & 2.15 & 2.08 \\
FEV1\% pred & $105(14)$ & $101(11)$ & $103(12)$ & $102(14)$ \\
Reversibility in FEV1\% & $2.6(5.1)$ & $1.9(7.2)$ & $4.2(4.7)$ & $3.3(5.4)$ \\
PEF morning L.min -1 & $260(86)$ & $272(81)$ & $245(71)$ & $237(63)$ \\
PEF morning \% pred & $86(17)$ & $91(16)$ & $86(14)$ & $85(14)$ \\
Methacholine PD20 $\mu$ mol & 3.67 & 4.14 & 3.74 & 3.02 \\
Maximum fall in FEV 1 & & & & \\
after exercise test \% & 8.4 & 11 & 12.3 & 9.6 \\
\hline Resur ary
\end{tabular}

Results are given as mean values with SD in parentheses. BUD: budesonide; FEV1: forced expiratory value in one second; PEF: peak expiratory flow; PD20: provocative dose causing a $20 \%$ fall in FEV1. (table 1). The mean FEV1 was $103 \%$ predicted and the mean reversibility in FEV1 was 3\%. Atopy was diagnosed in $67.5 \%$ of the children. Three patients were withdrawn from the study after randomization (all from the BUD 100 $\mu \mathrm{g}$ once-daily group), two of these because their asthma deteriorated and one due to noncompliance. At entry, the treatment groups were comparable regarding the number of patients, mean age, mean height and number of atopic patients. The proportion of females and males varied between the groups, as did baseline mean values for PEF and FEV1, with the placebo group having the lowest mean values (table 1).

\section{Exercise-induced bronchoconstriction}

The mean maximum fall in FEV1 (\% fall from pre-exercise value) after the exercise test at baseline is presented in table 1 . After 12 weeks of treatment, the corresponding values were: $4.3 \%$ for the BUD $100 \mu \mathrm{g}$ twice-daily group, $5.1 \%$ for the BUD $200 \mu \mathrm{g}$ once-daily group, $5.0 \%$ for the BUD $100 \mu \mathrm{g}$ once daily group and $8.6 \%$ for the placebo group (fig. 1). All pairwise comparisons of active treatment versus placebo revealed statistically significant differences, with no differences between the active treatments (table 2).

\section{Methacholine hyperreactivity}

The mean percentage increase in PD20 ( $\mu \mathrm{mol})$ from baseline to end of treatment was $110 \%$ in the BUD $100 \mu \mathrm{g}$ twice-daily group, $40 \%$ in the BUD $200 \mu \mathrm{g}$ once-daily group, $60 \%$ in the BUD $100 \mu \mathrm{g}$ once-daily group, and $40 \%$ in the placebo group.

Pairwise comparison of active treatments versus placebo revealed a statistically significant difference between BUD $100 \mu \mathrm{g}$ twice daily and placebo, with an estimated treatment effect ratio of $156 \%$ in favour of the BUD group (table 3).

\section{Lung function}

Baseline morning PEF values varied considerably among the four treatment groups (table 1). However, changes

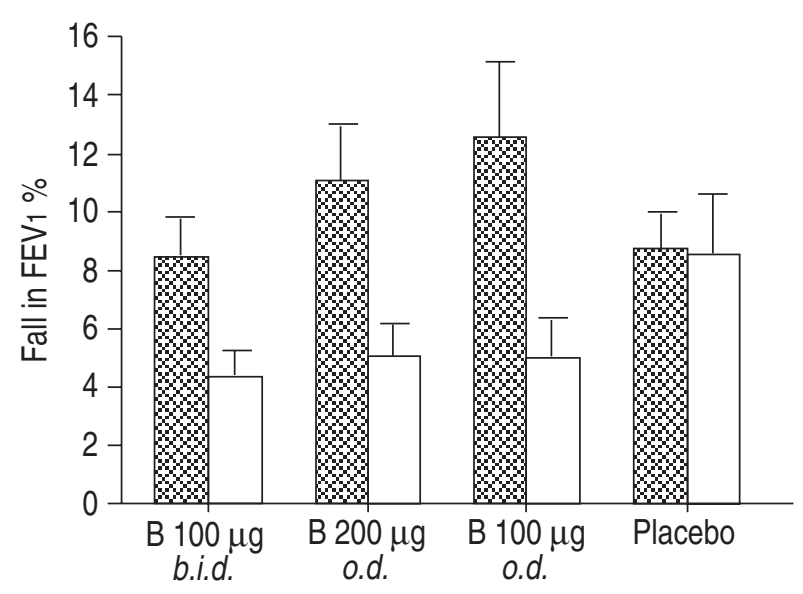

Fig. 1. - Comparison between different treatment effects on maximum fall in the forced expiratory volume in one second (FEV1). B: budesonide after exercise test ( $\%$ fall from pre-exercise value) from baseline to week 12. $\$$ : Baseline; $\square$ : week 12 . 
Table 2. - Comparison between different treatment effects, on maximum fall in forced expiratory volume in one second $\left(F E V_{1}\right)$ after exercise test (\% fall from pre exercise value) after 12 weeks of therapy

\begin{tabular}{lccc}
\hline Treatment group & $\begin{array}{c}\text { Estimated } \\
\text { difference in } \\
\text { fall FEV1\% }\end{array}$ & CI & p-value \\
\hline BUD 100 b.i.d./Placebo & -4.19 & $-7.6--0.8$ & 0.01 \\
BUD 100 o.d./Placebo & -4.69 & $-8.1--1.3$ & $<0.01$ \\
BUD 200 o.d./Placebo & -4.15 & $-7.5--0.8$ & 0.015 \\
BUD 200 o.d./BUD 100 b.i.d. & -0.05 & $-3.3-3$ & Ns \\
BUD 200 o.d./BUD 100 o.d. & 0.54 & $-2.8-3.9$ & Ns \\
\hline
\end{tabular}

CI: 95\% confidence interval; BUD: budesonide; ns: nonsignificant.

from baseline did not differ between the groups throughout the treatment period. A pairwise comparison between the different treatment groups showed no significant differences (table 4). An analysis of change in PEF (\% pred) gave consistent results as compared with the change in actual PEF values.

A statistically significant difference in FEV1 was only found between BUD $100 \mu \mathrm{g}$ twice daily and placebo $(0.1$ $\mathrm{L}, \mathrm{p}=0.015$ ). At the end of the treatment period, no statistically significant difference was found between the treatment groups in FEF25\%, whereas there was a significant difference in both FEF50\% (0.3 L, p=0.001) and FEF75\% $(0.1 \mathrm{~L}, \mathrm{p}=0.039)$ between BUD $100 \mu \mathrm{g}$ twice daily and placebo, and also between BUD $100 \mu \mathrm{g}$ twice daily and BUD $200 \mu \mathrm{g}$ once daily (FEF50\%: $0.3 \mathrm{~L}, \mathrm{p}=0.002$; FEF75\%: $0.1 \mathrm{~L}, \mathrm{p}=0.04)$ in favour of the BUD $100 \mu \mathrm{g}$ twice-daily group. Moreover, FEV1 (\% pred) showed a difference between BUD $100 \mu \mathrm{g}$ twice daily and placebo (5.2\%, $\mathrm{p}=$ 0.008 ) and between BUD $100 \mu \mathrm{g}$ twice daily and BUD $200 \mu \mathrm{g}$ once daily $(4.1 \%, \mathrm{p}=0.035)$ in favour of the BUD $100 \mu \mathrm{g}$ twice-daily group.

Resistance of the respiratory system (Rrs) and airway conductance $(G$ aw) differed significantly between BUD 100 $\mu \mathrm{g}$ twice daily and placebo (estimated ratio $R \mathrm{rs} 89.3 \%$, $\mathrm{p}=0.03$; estimated ratio $G$ aw $115.2 \%, \mathrm{p}=0.006)$. In a pairwise comparison between the groups, no other significant differences for $G$ aw and $R$ rs were found.

\section{Symptom scores}

Mean values for asthma symptoms were low throughout the study for all treatment groups. The mean symptom scores were already low at baseline, with a daytime mean symptom score of 0.39 and a night-time mean symptom score of 0.16 .

Table 3. - Provocative dose of methacholine ( $\mu \mathrm{mol}$ ) causing a $20 \%$ fall in the forced expiratory volume in one second: estimated ratio between treatment effects after 12 weeks of therapy

\begin{tabular}{lcrc}
\hline Treatment group & $\begin{array}{c}\text { Estimated } \\
\text { ratio } \%\end{array}$ & CI & p-value \\
\hline BUD 100 b.i.d./Placebo & 156 & $101.5-239.1$ & 0.04 \\
BUD 100 o.d./Placebo & 121 & $78.3-186.7$ & NS \\
BUD 200 o.d./Placebo & 107 & $70.0-163.5$ & Ns \\
BUD 100 b.i.d./BUD 200 o.d. & 146 & $95.4-222.2$ & Ns \\
BUD 200 o.d./BUD 100 o.d. & 89 & $57.7-135.9$ & NS
\end{tabular}

CI: 95\% confidence interval; BUD: budesonide; ss: nonsignificant.
Table 4. - Comparison between different treatment effects on change in peak expiratory flow after 12 weeks of therapy

\begin{tabular}{lccc}
\hline Treatment group & $\begin{array}{c}\text { Estimated } \\
\text { difference } \\
\text { L.min-1 }\end{array}$ & 95\% CI & p-value \\
& 5.8 & $-8.1-19.7$ & Ns \\
\hline BUD 100 b.i.d./Placebo & 3.0 & $-10.8-16.8$ & Ns \\
BUD 100 o.d./Placebo & 2.9 & $-11.0-16.7$ & Ns \\
BUD 200 o.d./Placebo & 2.9 & $-10.8-16.6$ & Ns \\
BUD 200 o.d./BUD 100 b.i.d. & -0.1 & $-13.9-13.6$ & Ns \\
BUD 200 o.d./BUD 100 o.d. &
\end{tabular}

Adjusted means from the analysis of variance and $95 \%$ confidence interval (CI). BUD: budesonide; ss: nonsignificant.

Statistically significant differences in symptoms during the night were found between BUD $200 \mu \mathrm{g}$ once daily and placebo $(-0.11, \mathrm{p}=0.047)$, as well as between BUD $200 \mu \mathrm{g}$ once daily and BUD $100 \mu \mathrm{g}$ once daily $(-0.11, \mathrm{p}=0.040)$. This applied to both the mean symptom score and the frequency of symptom-free nights.

At baseline, the children used a mean number of 0.49 $\beta_{2}$-agonist inhalations during the day and 0.11 inhalations during the night. There were no significant differences in mean change from baseline between the treatment groups.

\section{Adverse events}

The adverse event profile observed in the three active treatment groups was similar to that reported for the placebo group. The most common adverse events were respiratory infection, coughing, and headache. One adverse event was regarded as serious: one patient receiving placebo experienced pharyngitis and high fever and was admitted to hospital for 3 days. A causal relationship to the study drug was judged unlikely. None of the patients discontinued the study because of adverse events.

\section{Discussion}

The present study in children with asthma shows that a low dose of BUD, administered once or twice daily for 12 weeks, protects against an exercise-induced reduction in lung function.

The once-daily morning regimens were shown to be as effective as the twice-daily dosing regimen with regard to the protective effect against exercise-induced asthma.

The majority of the patients selected for the present study had mild asthma, mild being defined as low-grade symptoms that did not interfere with sleep and lifestyle, or episodes of cough and wheeze occurring less than once a month [1]. Patients were selected on the basis of known asthma symptoms in the past year and not because of previously documented bronchial hyperresponsiveness. The fact, that mean reversibility was only $3 \%$ after inhalation of a bronchodilator and that FEV1 at baseline showed a mean value of $>100 \%$ pred indicate that the patients had near-normal lung function at baseline with little room for improvement. The mean bronchodilator use at baseline was 0.6 inhalations $\cdot 24 \mathrm{~h}^{-1}$. This relatively high use in this group of patients with mild disease can partly be explained by the fact that many of the children were using a bronchodilator routinely before exercise. 
PEF, which is often used when evaluating the effect of inhaled steroid treatment, was shown to be a less sensitive measure than an exercise test in detecting treatment effects in the present study in children with near normal lung function and mild symptoms. The results of the peak flow measurements failed to demonstrate any statistically significant difference between the active treatments and placebo.

In a study on children with moderate to severe asthma (PEF 55\% pred), PeDERSEN and Hansen [11] found that an exercise test is a more sensitive parameter than PEF and FEV1 in detecting differences between various doses of BUD. Even low doses of BUD, approximately $100 \mu \mathrm{g}$. day $^{-1}$ showed marked effects. This also proved to be true in this study in patients with mild asthma, where all active treatments provided better protection against exerciseinduced bronchoconstriction than did placebo.

The results are important and useful for future studies, since protection against exercise-induced asthma may be used as a sensitive measure of the efficacy of inhaled steroids, which may reveal differences between different treatments that are not apparent when standard lung function tests are used. The result of the PEF data obtained in this study is supported by a study by UwYYED et al.[18], where it was concluded that PEF monitoring is not sensitive enough to register meaningful changes in children and young adults with mild asthma (FEV1 $82 \%$ pred and PEF $87 \%$ pred).

WAALKENS et al.[19] compared the effects of treatment with budesonide $200 \mu \mathrm{g}$ twice daily and terbutaline with the effects of terbutaline alone in a placebo-controlled, double-blind study in 27 children with mild asthma (FEV1 93\% pred) over 8 weeks. They found that mean FEV1 did not change in either group and that there was no significant change in morning PEF, although they found a significant difference in favour of BUD for evening and nocturnal PEF. Airway hyperresponsiveness (provocative concentration of histamine causing a 20\% fall in FEV1 (PD20)) decreased in the BUD/terbutaline-treated patients compared with the placebo/terbutaline group.

In the present study, the methacholine PD20 was significantly larger in the children receiving BUD $100 \mu \mathrm{g}$ twice daily than in those receiving placebo. The differences in PD20 in the two other treatment groups were not statistically significant, compared with placebo, although there were numerical increases in all treatment groups. $\mathrm{V}_{\mathrm{AN}}$ ESSEN-ZANDVLIET et al. [20] showed that a reduction in the direct nonspecific bronchial responsiveness (PD20 for histamine) increases gradually and first stabilizes after 20 months of treatment with inhaled budesonide in children with asthma. These findings can partly explain the weak response in the methacholine challenge test in the present study, with a treatment period of only 3 months.

With respect to spirometry, the high baseline FEV1 values (>100\% pred) and poor reversibility gave little room for improvement. Although statistically significant, the increase in FEV1 in the twice-daily group was small. As pointed out by FERGUSON [21], FEF25-75 is a more sensitive indicator of airflow than PEF or FEV1. He suggest- ed that frequent assessment of FEF25-75 is required for optimal assessment of the effectiveness of therapy. In the present study this is demonstrated by the finding of a significant difference between BUD $100 \mu \mathrm{g}$ twice daily and placebo as well as between BUD $100 \mu \mathrm{g}$ twice daily and
BUD $200 \mu \mathrm{g}$ once daily for FEF50\% and FEF75\%, otherwise the results were consistent when compared to FEV1 or PEF.

The effect of switching from twice-daily to once-daily treatment with budesonide in well-controlled asthmatic children was studied by McCARTHY [22] and MölleR et al.[23]. They found that PEF, FEV1, symptom scores and bronchodilator use during once-daily treatment were not different from those during twice-daily treatment.

In summary, the present study showed that low doses of inhaled budesonide administered at a dose of $100 \mu \mathrm{g}$ or $200 \mu \mathrm{g}$ once daily or $100 \mu \mathrm{g}$ twice daily via Turbuhaler ${ }^{\circledR}$ provided protection against exercise-induced bronchoconstriction in children with mild asthma and that all three treatment regimens were well tolerated. An exercise test is suggested to be more sensitive than peak expiratory flow and forced expiratory volume in one second, in evaluating the efficacy of treatment with inhaled steroids in asthmatic children with mild disease and near-normal lung function.

Acknowledgements: Astra Draco AB, Lund, Sweden, supplied budesonide, terbutaline and placebo Turbuhaler ${ }^{\circledR}$ inhalers, as well as diaries and case report forms. The authors thank E. Edvardsen, C. Jonasson and B. Stache for their help and assistance, J. Leegaard and J. Grøgaard for their support and J. Ekelund for statistical help.

\section{References}

1. Warner JO, Neijens H, Landau LI. Asthma: a follow up statement from an international paediatric asthma consensus group. Arch Dis Child 1992; 67: 240-248.

2. Expert Panel Report II. Guidelines for the Diagnosis and Management of Asthma. National Asthma Education and Prevention Program. National Institutes of Health, February 1997.

3. Agertoft L, Pedersen S. Effects of long-term treatment with an inhaled corticosteroid on growth and pulmonary function in asthmatic children. Respir Med 1994; 88: 373-381.

4. König P, Shaffer J. The effect of drug therapy on long term outcome of childhood asthma: a possible preview of the international guidelines. J Allergy Clin Immunol 1996; 98: 1103-1111.

5. Woodhead M. Guidelines on the management of asthma. Thorax 1993; 48: S1-S24.

6. Pedersen S. Safety aspects of corticosteroids in children. Eur Respir Rev 1994; 4: 33-43.

7. Clark DJ, Grove A, Cargill RI, Lipworth BJ. Comparative adrenal suppression with inhaled budesonide and fluticasone propionate in adult asthmatic patients. Thorax 1996; 51: 262-266.

8. Lönnebo A, Grahnén A, Jansson B, Brundin RM, Ling-Andersson A, Eckernäs S- $\AA$. An assessment of the systemic effects of single and repeated doses of inhaled fluticasone propionate and inhaled budesonide in healthy volunteers. Eur J Clin Pharmacol 1996; 49: 459-463.

9. Price JF, Weller PH. Comparison of fluticasone proprioanate and sodium cromoglycate for the treatment of childhood asthma (an open parallel group study). Respir Med 1995; 89: 363-368.

10. Volovitz B, Amir J, Malik H, Kauschansky A, Varsano I. Growth and pituitary-adrenal function in children with severe asthma treated with inhaled budesonide. $N$ Engl $J$ Med 1993; 329: 1703-1708. 
11. Pedersen S, Hansen OR. Budesonide treatment of moderate and severe asthma in children: A dose-response study. J Allergy Clin Immunol 1995; 95: 29-33.

12. Sheffer AL, Bousquet J, Busse WW, et al. International consensus report on diagnosis and treatment of asthma. Eur Respir J 1992; 5: 601-641.

13. Anonymous. Nordic consensus report. In: Nordiska Samarbetsnämnden för Medicinsk Forskning (NOS). Stockholm, Spri, 1992; pp. 19-20.

14. Oseid S, Haaland K. Exercise studies on asthmatic children before and after regular training. In: Erikson B, Furberg B, eds. Swimming Medicine IV. Baltimore, MD, University Park Press, 1978; pp. 32-41.

15. Yan K, Salome C, Woolcock AJ. Rapid method for measurement of bronchial responsiveness. Thorax 1983; 38: 760-765.

16. Cockroft DW, Berscheid BA. Slope of the dose-response curve: usefulness in assessing bronchial response to inhaled histamine. Thorax 1983; 38: 55-61.

17. Zapletal A, Samanek M, Tuma S, Ruth C, Paul T. Assessment of airway function in children. Bull Physiopathol Respir 1972; 8: 535-543.

18. Uwyyed K, Springer C, Avital A, Bar-Yishay E, Godfrey $\mathrm{S}$. Home recording of PEF in young asthmatics does it contribute to management? Eur Respir J 1996; 9: 872879.

19. Waalkens HJ, Gerritsen J, Koëter GH, Krouwels FH, van Aalderen WMC, Knol K. Budesonide and terbutaline or terbutaline alone in children with mild asthma: effects on bronchial hyperresponsiveness and diurnal variation in peak flow. Thorax 1991; 46: 499-503.

20. Van Essen-Zandvliet EE, Hughes MD, Waalkens HJ, Duiverman EJ, Pocock SJ, Kerrebijn KF. Effects of 22 months treatment with inhaled corticosteroids and/or beta2-agonists on lung function, airway responsiveness and symptoms in children with asthma. Am Rev Respir Dis 1992; 146: 547-554.

21. Ferguson AC. Persisting airway obstruction in asymptomatic children with asthma with normal peak expiratory flow rates. J Allergy Clin Immunol 1988; 82: 19-22.

22. McCarthy TP. The use of a once daily inhaled glucocorticosteroid (budesonide) in the management of childhood asthma. Br J Clin Res 1993; 4: 55-61.

23. Moller C, Strømberg L, Oldaeus G, Arweström E, Kjellman M. Administration of budesonide via Turbuhaler ${ }^{\circledR}$ ( $200 \mu \mathrm{g}$ and $400 \mu \mathrm{g}$ ) once daily is as effective as when given twice daily in children with asthma. Eur Respir $J$ 1996; 9: Suppl. 23, 115s. 